\title{
Policy Practice Dilemma in the Interests of the Environmental Case
}

\author{
Serach Heipakhon ${ }^{1}$, Telaphon Seruchart ${ }^{1}$, Do Somphorn ${ }^{2}$ \\ ${ }^{1}$ Faculty of Political Science, Chulalongkorn University, Thailand \\ ${ }^{2}$ Faculty of Political Science, Thammasat University, Thailand \\ Received: August 15, 2021 \\ Received in Revised: September 9, 2021 \\ Accepted: September 19, 2021
}

\begin{abstract}
The purpose of the study to ensuring legal certainty and order in the operation of buildings, each building must comply with the administrative and technical requirements of the building, and all work must be completed in a timely manner. There is always an apparent struggle over whether to take a position in favor of the environment or not. It is essential to exercise extreme caution in order to avert the potential of even higher losses to humanity. This study considered scenarios that may be faced by a variety of different administrations.
\end{abstract}

Keywords: Policy Practice, Environmental Case, Legal Certainty

\section{Introduction}

The construction of a structure is one of the physical manifestations of space use. The spatial arrangement of the structure is still referred to as the building arrangement in line with the relevant rules and regulations (Raven et al., 2019) for the purpose of ensuring legal certainty and order in the operation of buildings, each building must comply with the administrative and technical requirements of the building, and all work must be completed in a timely manner.

Construction and demolition of buildings are governed by the Law on Buildings, which regulates their function and requirements, as well as their operations, which includes provisions on the rights and obligations of the building owner and user at each stage of the construction and demolition process, provisions on the community's role and government guidance at each stage of the construction and demolition process, sanctions, transitional provisions, and closing.

Throughout the regulation, the concepts of benefit, safety, balance, and harmony of the building with its surroundings are taken into consideration, all for the benefit of a humane and fair society as a whole.

Communities are encouraged to become involved and play an active role not only in the context of the construction and utilization of buildings for their own purposes, but also in improving the fulfilment of building requirements and the overall management of buildings in a systematic and orderly fashion (Veloutsou \& Black, 2020).

The realization of the building is also inextricably linked to the role of the construction service provider as defined by the applicable legislation in the field of construction services, whether as planners, implementers, supervisors, or construction managers, or as providers of development services, which may include providers of building technical review services, among other things. The regulation of this building must be coordinated with the provision of construction services in compliance with applicable laws and regulations (Yang \& Li, 2018).

Because of the passage of this law, all building operations, including both construction and utilization, carried out by the government, the private sector, the public, and foreign parties are now required to comply with all provisions of the Law on Buildings, including those pertaining to construction and utilization. 
When dealing with and responding to technological advancements, both in information technology and in architecture and engineering, it is necessary to have a balanced application that takes into consideration the socio-cultural values of the local community as well as the existing architectural and environmental characteristics, particularly contextual, traditional, specific, and historic values, while maintaining a sense of proportion.

The provisions of this legislation also include measures for taking into account the very varied social, economic, and cultural circumstances that exist in the society. This is why the government continues to encourage, empower, and improve the ability of the community to meet the provisions in stages so that guarantees of security, safety, and public health in organizing buildings and their environments can be enjoyed by all parties fairly and imbued with the spirit of humanity, togetherness, and helping one another, as well as imbued with the implementation of international standards.

\section{Building and Environment}

An architectural structure created through construction work that is integrated with its residence and partially or entirely located above, in, or on the land and/or water, and that is used as a place for humans to carry out their activities, whether for housing or residence, religious activities, commercial operations, social events or special events.

When a building is being constructed, it is considered a development activity since it involves the processes of technical design and construction execution, as well as activities such as usage, preservation, and destruction (Omwoma et al., 2017). Using buildings is the action of putting them to use in line with specified functions. This includes things like routine maintenance, preventative maintenance, and periodic inspections.

Maintenance is an action that is performed to ensure that a building's dependability, as well as its infrastructure and amenities, are maintained so that it is always operational (Ruparathna et al., 2017). In the construction industry, maintenance is defined as the process of repairing and/or replacing building parts, components, building materials, and/or infrastructure and facilities in order for the building to stay operational (Stephan \& Athanassiadis, 2018).

Periodic inspection is the process of evaluating the dependability of a building, its components, construction materials, and/or its infrastructure and facilities over a certain period of time in order to determine whether or not the facility is in good working condition (Prakash et al., 2021). Preservation is the upkeep, repair, and maintenance of structures and their surrounding environments in order to restore the structural integrity of the structure to its original state or to the circumstances that are appropriate for the duration of the desired time (Leeds, 2017).

In construction, demolition is the process of dismantling or destroying a building, its components, construction materials, and/or its infrastructure and amenities (Cai \& Waldmann, 2019). Building ownership is defined as a person, legal entity, group of people or organization that is legally recognized as the building's owner under applicable legislation. a person, legal entity, group of people or association (Mulyani, 2020). In accordance with the stated function, building users may be either building owners or non-building owners who have entered into an agreement with the building owner. Building users utilize and/or administer the building or a portion of the building in accordance with the given function.

Generally speaking, a technical reviewer is a person or legal organization that has a certificate of competence and is authorized to conduct technical evaluations of the feasibility of building functions in line with the requirements of the relevant law (Gibreel et al., 2019). Individuals, groups, legal entities or companies, as well as institutions or organizations involved in the 
construction industry, including customary law communities and expert communities, who have an interest in building management are considered to be members of the community.

\section{Dilemma in Plastic and Paper Bag}

According to the findings of the study, plastic bags must be reused four times in order to offset the emissions equivalent to the production of one single-use plastic bag. Paper bags and cotton bags have a significantly higher environmental impact than other types of bags because of the possibility of poisoning during the manufacturing process. When it comes to negative environmental effects, the paper bag manufacturing process, which uses huge quantities of water and natural resources, is a significant contributor. As a result, enhancing manufacturing techniques, maximizing resource use, and adhering to future sustainable practices may all contribute to the continued usage of cotton and paper bags.

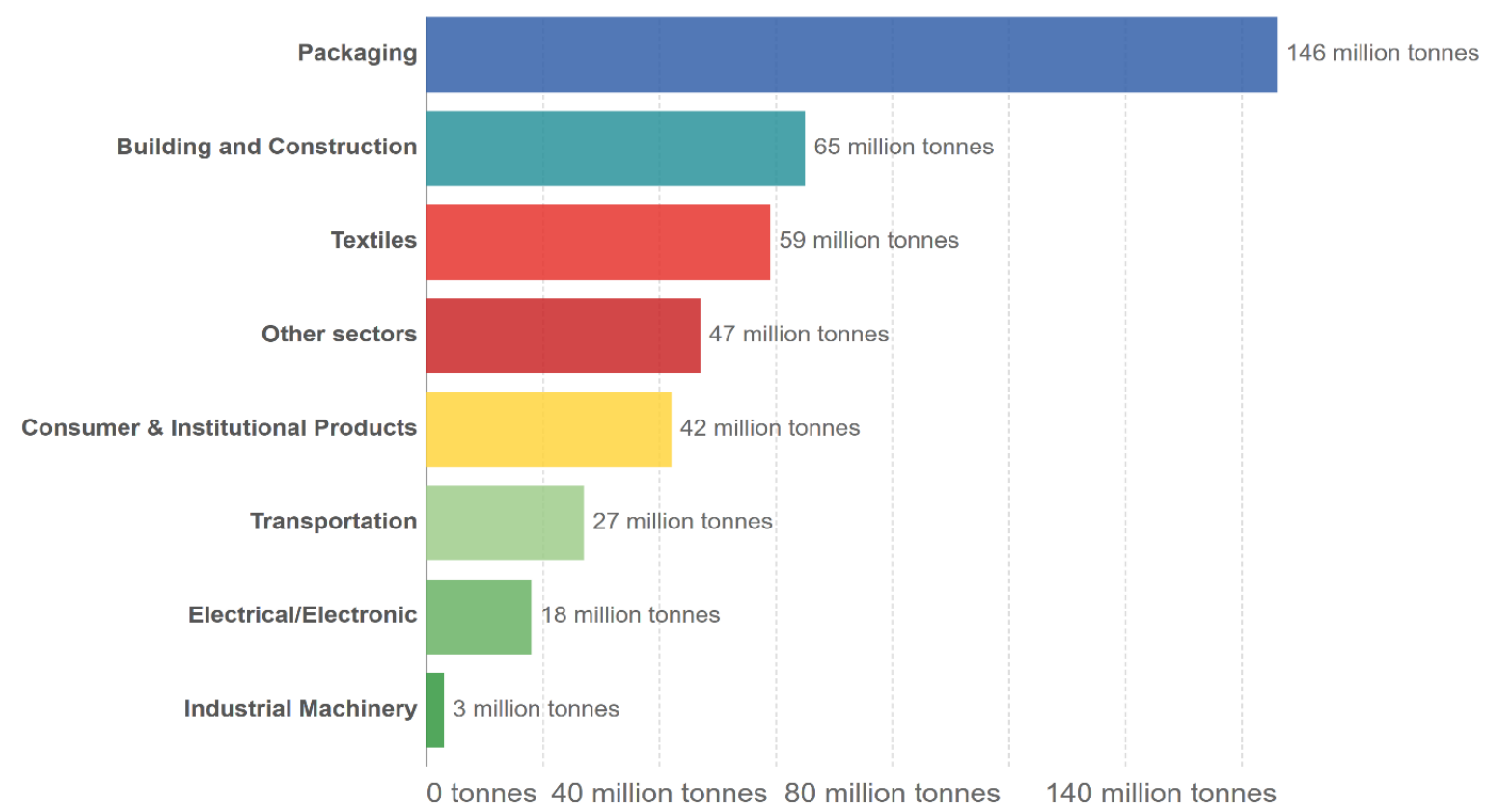

Figure 1. Primary Plastic Production by Industrial Sector

Source: (Geyer et al., 2017)

As a result, it is essential to consider the consequences of each individual situation while dealing with plastic trash. As long as there is no substantial leakage of trash into the environment, utilizing plastic bags in a well-structured closed urban waste management system that includes incinerator treatment may prove to be the most cost-effective alternative. The strategy of applying excise tax or charging for plastic bags has always had both advantages and disadvantages in the eyes of the public (Walker et al., 2020). This is inextricably linked to the policy's advantages and disadvantages. It is anticipated that restrictions on plastic circulation via payment methods would have a positive impact on the environment.

In this case, the substitution of plastic bags with more ecologically friendly alternatives such as cloth bags is advantageous. Every year, the general population utilizes about 9.8 billion pieces of plastic bags. Up to 95 percent of plastic bags are thrown away as trash, and plastic is difficult for the environment to breakdown due to its chemical composition. The use of paid plastic bags has been adopted effectively in Hong Kong, the United Kingdom, and the Netherlands. According to data from the three nations, the paid plastic bag program has resulted in a reduction in plastic use of up to 73 percent. 
As a result, there is reason to be optimistic about the decrease of plastic trash. In contrast, it has the economic capability of creating possibilities for the circulation of ecologically friendly bags in a cost-effective manner. This bag may be created from any kind of fabric, even leftovers (waste). It is possible for new economic companies to develop at the same time in an integrated waste management cycle by using textile waste generated by other businesses.

The strategy of charging for plastic bags is not without its drawbacks. If the transition from paper to plastic bags does not go smoothly, this strategy will actually enhance the revenue of the store by increasing the number of plastic bags sold. This policy appears to be a form of simplification, as it does not appear to necessitate strict oversight. A severe prohibition on the use of plastic bags in contemporary stores and marketplaces, on the other hand, is a very other proposition. Furthermore, the focus is restricted to contemporary stores, while the greatest circulation is found exactly in old shops or markets, which is a drawback. There are still some notes on the findings made in the field. Even now, several retail establishments have not adopted the new policy. Subterfuge is used by certain people to get what they want. Plastic bags are purchased, but they are reduced again and again until they are no longer necessary.

\section{Policy on Vehicle}

In an attempt to decrease the generation of carbon emissions from motor vehicles, the government is taking steps to do so. With the introduction of the LCEV (Low Carbon Emission Vehicle), it is anticipated that this program will contribute to the achievement of the goal of 20 percent of environmentally friendly cars in total vehicle production by 2025. Although there are numerous obstacles to overcome, some of the most significant are those related to public acceptance of electrified vehicles, driving comfort, energy charging infrastructure electricity, domestic supply chains, adoption of technology and regulatory frameworks, as well as support for fiscal and non-fiscal policies (Burkert et al., 2021). Aim: To make it possible for the general population to use electric cars without incurring prohibitively large extra expenses.

In order to encourage the Main Component Industry to grow, the first approach is to offer fiscal incentives in the form of a Tax Holiday/Mini Tax Holiday. Industry sectors that qualify for tax allowances include the battery component industry, the electric motor industry (magnets and motor coils), as well as tax allowances for new and expanding businesses. Next, special agreements relating to import duties and other taxes, including local taxes, are being considered to help the electric car sector get off the ground more quickly (Electrified Vehicle). In addition, the development of new export markets is being pursued via the negotiation of Preferential Tariff Agreements with nations that have a strong need for motorized transportation (Hoang \& Sicurelli, 2017).

According to reports, the Japanese government is now planning to phase out sales of internal combustion engine automobiles in the nation by the middle of 2035 in order to support the Suga goal. Japan's Ministry of Economy and Trade is contemplating prohibiting the sale of this kind of vehicle, according to a report in Just Auto. The goal is to speed the transition to pure electric and hybrid vehicles.

Toyoda went on to say that if Japan was too quick in banning gasoline-powered automobiles, the existing economic model for the automobile industry would most certainly collapse. It is estimated that millions of employments will be eliminated as a result of this impact. Another point that Toyoda brought up was the fact that the majority of Japan's power plants are fueled by coal and natural gas combustion. It is claimed that just switching to an electric vehicle would not assist to decrease carbon emissions.

Global energy consumption from electric vehicles is expected to reach 1,800 terawatt hours by 2040, which is about five times the present electricity usage in the United Kingdom. According

Copyright $\odot$ 2021, Journal of Asian Multicultural Research for Social Sciences Study, Under the license CC BY-SA 4.0 
to statistics from the United Kingdom, the energy used by electric vehicles would result in an additional 510 megatons of carbon dioxide emissions from the electrical industry globally. Electricity produced completely from renewable energy sources, rather than fossil fuels, may have a significant effect on reducing this enormous impact.

According to calculations, 510 Megatons is equal to about 1.6 percent of worldwide carbon dioxide emissions in 2018. Meanwhile, this does not seem to be a significant amount of money. Global carbon emissions should be reduced to zero by 2050, according to the Intergovernmental Panel on Climate Change (IPCC), in order to keep the average global temperature, increase to 1.5 degrees Celsius over pre-industrial levels (Rhodes, 2019). Therefore, a rise in carbon dioxide emissions of 1.6 percent is a significant concern that has the potential to become a big issue in the near future.

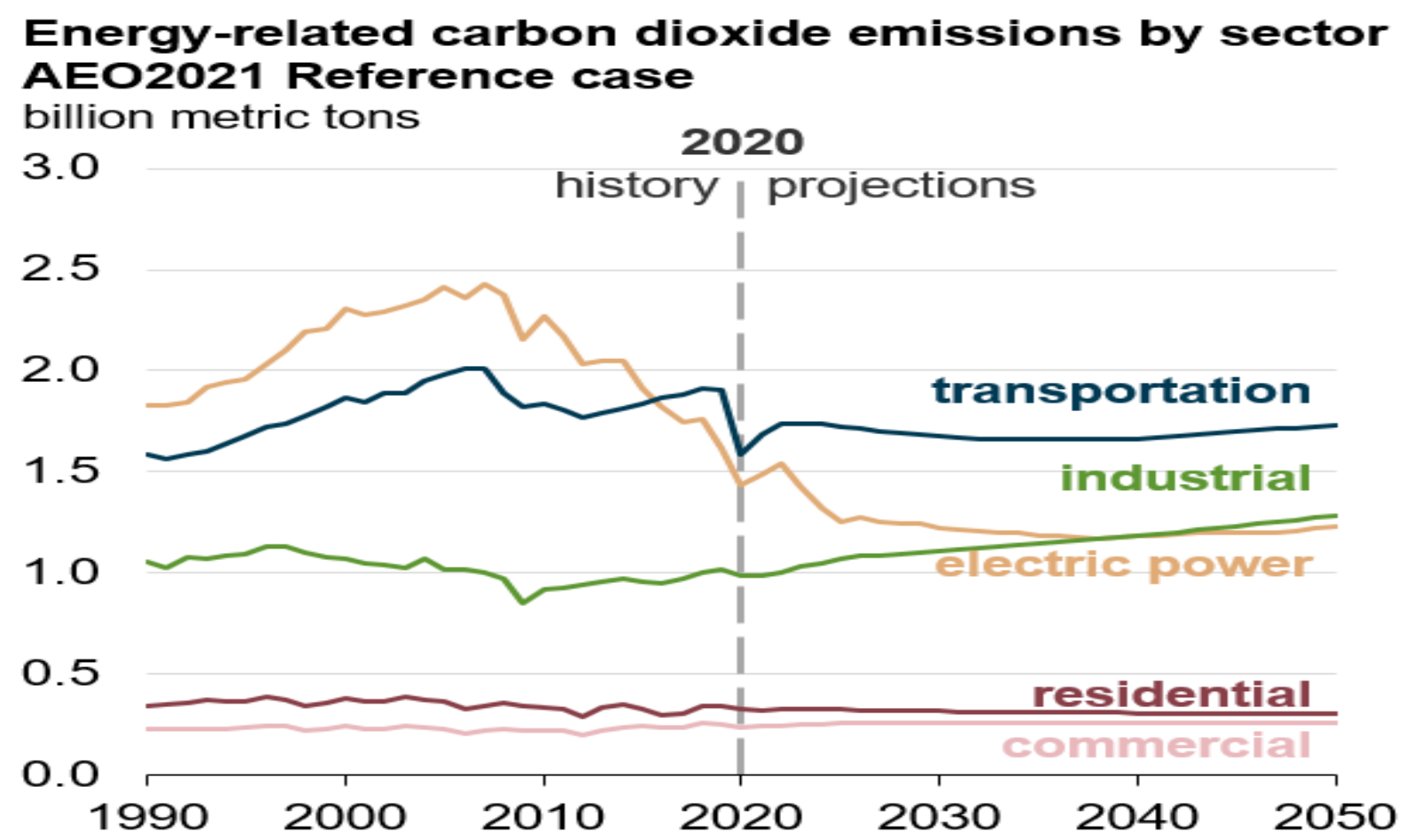

Figure 2. Carbon dioxide emission by sector

Source: U.S. Energy Information Administration, Annual Energy Outlook 2021, February 2021

Most likely, this rise may be mitigated by decreasing emissions, which will result from the progressive phaseout of environmentally harmful automobiles. To be sure, lowering global carbon emissions is not an easy task. In reality, emissions reached their greatest level in 2018, despite the fact that the amount of renewable energy usage reached its highest level as well. Despite the fact that electric vehicles emit much less emissions than conventional vehicles, the manufacturing process for electric vehicles, as well as the production of renewable energy technologies, generates carbon dioxide.

One of the most significant challenges facing electric vehicles is the availability, manufacturing, and supply of rare earth metals and other naturally occurring elements. Electric vehicles include valuable metals such as lithium and cobalt in their batteries, which are used to power them. Cobalt is a rare metal that is already posing a danger to the manufacturing of electric automobiles due to scarcity (Ballinger et al., 2019). Alternative designs that do not depend on limited materials are being investigated by automakers right now. 
There is a plethora of recycling facilities that are needed to treat rare metals and other materials for electric vehicles so that they may be reused. Another issue is the intention to decrease the number of conventional cars on the road by disposing of them at the Final Disposal Site. It is just impossible to do.

Another issue that makes it difficult for electric vehicles to contribute to the reduction of global emissions and the prevention of climate disaster is that people prefer to charge their electric vehicles in the evenings after they get home from work. Consequently, the energy grid becomes more active at night, which may create difficulties for power distribution and transmission systems at the community or municipal level (Olivella-Rosell, 2018).

It's possible that this refuelling system may need to be fixed. It is also possible for energy providers to charge higher prices during peak hours while charging cheaper tariffs outside of peak hours or during periods of low power demand. Users will be encouraged to charge their electric vehicles during off-peak hours as a result of this research.

\section{Conclusion}

When it comes to policy procedures, there is always some kind of seeming conflict about whether to side with the environmental cases or not. It is necessary to take a very cautious approach in order to reduce the possibility of even greater costs to mankind. The question is no more whether or whether the government should prioritize its yearly revenue via taxes, but rather which method is the most advantageous. This research has taken into account situations that might potentially be encountered by many different administrations.

\section{References}

Ballinger, B., Stringer, M., Schmeda-Lopez, D. R., Kefford, B., Parkinson, B., Greig, C., \& Smart, S. (2019). The vulnerability of electric vehicle deployment to critical mineral supply. Applied Energy, 255, 113844.

Burkert, A., Fechtner, H., \& Schmuelling, B. (2021). Interdisciplinary Analysis of Social Acceptance Regarding Electric Vehicles with a Focus on Charging Infrastructure and Driving Range in Germany. World Electric Vehicle Journal, 12(1), 25.

Cai, G., \& Waldmann, D. (2019). A material and component bank to facilitate material recycling and component reuse for a sustainable construction: Concept and preliminary study. Clean Technologies and Environmental Policy, 21(10), 20152032.

Geyer, R., Jambeck, J. R., \& Law, K. L. (2017). Production, use, and fate of all plastics ever made. Science advances, 3(7), e1700782.

Gibreel, H. E. H., Ahmed, M. M., Sam, A. K., \& Suliman, I. I. (2019). Evaluation of Sudan Nuclear and Radiological Regulatory control act (2017) in light of IAEA safety standards. Progress in Nuclear Energy, 115, 158-168.

Hoang, H. H., \& Sicurelli, D. (2017). The EU's preferential trade agreements with Singapore and Vietnam. Market vs. normative imperatives. Contemporary Politics, 23(4), 369387.

Leeds, J. (2017). The New Lighthouse Keepers: A Comparative Analysis of Ownership Structures Under the National Historic Lighthouse Preservation Act Program (Doctoral dissertation, Clemson University). 
Mulyani, L. (2020). Reforming Group Legal Personhood in Indonesian Land Law: Towards Equitable Land Rights for Traditional Customary Communities (Doctoral dissertation).

Olivella-Rosell, P., Lloret-Gallego, P., Munné-Collado, Í., Villafafila-Robles, R., Sumper, A., Ottessen, S. Ø., ... \& Bremdal, B. A. (2018). Local flexibility market design for aggregators providing multiple flexibility services at distribution network level. Energies, 11(4), 822.

Omwoma, S., Lalah, J. O., Kueppers, S., Wang, Y., Lenoir, D., \& Schramm, K. W. (2017). Technological tools for sustainable development in developing countries: The example of Africa, a review. Sustainable Chemistry and Pharmacy, 6, 67-81.

Prakash, G., Yuan, X. X., Hazra, B., \& Mizutani, D. (2021). Toward a big data-based approach: A review on degradation models for prognosis of critical infrastructure. Journal of Nondestructive Evaluation, Diagnostics and Prognostics of Engineering Systems, 4(2), 021005.

Raven, R., Sengers, F., Spaeth, P., Xie, L., Cheshmehzangi, A., \& de Jong, M. (2019). Urban experimentation and institutional arrangements. European Planning Studies, 27(2), 258-281.

Rhodes, C. J. (2019). Only 12 years left to readjust for the 1.5-degree climate change optionSays International Panel on Climate Change report: Current commentary. Science progress, 102(1), 73-87.

Ruparathna, R., Hewage, K., \& Sadiq, R. (2017). Developing a level of service (LOS) index for operational management of public buildings. Sustainable cities and society, 34 , 159-173.

Stephan, A., \& Athanassiadis, A. (2018). Towards a more circular construction sector: Estimating and spatialising current and future non-structural material replacement flows to maintain urban building stocks. Resources, Conservation and Recycling, 129, 248-262.

Veloutsou, C., \& Black, I. (2020). Creating and managing participative brand communities: The roles members perform. Journal of Business Research, 117, 873-885.

Walker, T., Gramlich, D., \& Dumont-Bergeron, A. (2020). The case for a plastic tax: a review of its benefits and disadvantages within a circular economy. Sustainability.

Yang, D., \& Li, M. (2018). Evolutionary approaches and the construction of technology-driven regulations. Emerging Markets Finance and Trade, 54(14), 3256-3271. 